\title{
Lung maladies following aneurysmal subarachnoid haemorrhage
}

\author{
Gentle S. Shrestha
}

\begin{abstract}
Pulmonary complications are common in patients with aneurysmal subarachnoid haemorrhage. It is associated with adverse outcome in the form of higher incidence of vasospasm, poor neurological outcome, longer length of stay and higher mortality. These patients are at high risk for ventilator associated pneumonia. Preventive measures, early detection and timely appropriate treatment is important. Acute respiratory distress is common in patients with subarachnoid haemorrhage. Measures to minimize the second hit to the vulnerable lungs is crucial. Low tidal volume ventilation, application of PEEP and prone ventilation should be used with special emphasis to avoid hypercarbia and increase in intracranial pressure. Activation of sympathetic nervous system, release of catecholamine and damage to pulmonary endothelium can lead to neurogenic pulmonary edema. Treatment of underlying cause and supportive care is helpful.These patients are at high risk of deep vein thrombosis and pulmonary embolism. Measures to prevent deep vein thrombosis and administration of pharmacological prophylaxis when safe, needs to be considered.
\end{abstract}

Key words: Acute respiratory distress syndrome, aneurysmal subarachnoid haemorrhage, lung maladies, neurogenic pulmonary edema, pneumonia, pulmonary embolism

\section{INTRODUCTION}

In patients with aneurysmal subarachnoid haemorrhage (SAH), secondary complications are the important cause of morbidity and mortality. ${ }^{[1]}$ Pulmonary complications are the important causes of non-neurological medical complications in patients with aneurysmal SAH. ${ }^{[2,3]}$ Oxygenation disturbances occur in $43 \%-92 \%$ of patients with SAH. ${ }^{[4]}$ In patients with brain injury and respiratory failure, mechanical ventilation is associated with longer Intensive Care Unit (ICU) and hospital stay, poor neurological

Department of Anaesthesiology, Institute of Medicine, Tribhuvan University Teaching Hospital, Kathmandu, Nepal

Address for correspondence:

Dr. Gentle S. Shrestha, Department of Anaesthesiology,

Institute of Medicine, Tribhuvan University Teaching Hospital,

Maharajgunj, Kathmandu, Nepal.

E-mail: gentlesunder@hotmail.com

\begin{tabular}{|l|l|}
\hline \multicolumn{2}{|c|}{ Access this article online } \\
\hline Quick Response Code: & Website: \\
\hline & www.jnaccjournal.org \\
\cline { 2 - 3 } & \\
\hline & DOI: \\
\hline
\end{tabular}

outcomes, higher incidence of symptomatic vasospasm and increased mortality. ${ }^{[5,6]}$ The lung maladies in patients with aneurysmal SAH occurs in the form of ventilator-associated pneumonia (VAP), acute respiratory distress syndrome (ARDS) and neurogenic pulmonary oedema (NPE). ${ }^{[7]}$

\section{PNEUMONIA}

Patients with neurological disorders are at increased risk for developing aspiration pneumonia and VAP in part due to decreased level of consciousness and aspiration of gastric contents. ${ }^{[8]} \mathrm{VAP}$ is the most common nosocomial infection in patients with SAH and is associated with longer duration of mechanical ventilation and ICU stay. It is an independent predictor of mortality and severe disability. ${ }^{[9,10]}$ Methicillin-susceptible Staphylococcus aureus is the most common pathogen. Initiation of early enteral feeding, oral care and

This is an open access article distributed under the terms of the Creative Commons Attribution-NonCommercial-ShareAlike 3.0 License, which allows others to remix, tweak, and build upon the work non-commercially, as long as the author is credited and the new creations are licensed under the identical terms.

For reprints contact: reprints@medknow.com

How to cite this article: Shrestha GS. Lung maladies following aneurysmal subarachnoid haemorrhage. J Neuroanaesthesiol Crit Care 2017;4:S45-8. 
implementation of VAP prevention bundle can be beneficial to decrease the incidence of VAP. Unless contraindicated, daily interruption of sedation to assess readiness for extubation, maintaining endotracheal tube cuff pressure, hand hygiene, elevation of head-end of the bed, oral hygiene with chlorhexidine and stress-ulcer prophylaxis can together help decrease the incidence of pneumonia. The appropriate and timely institution of antibiotics and control of fever is necessary for a better outcome. ${ }^{[11-13]}$

\section{ACUTE RESPIRATORY DISTRESS SYNDROME}

ARDS is common in patients with injured brain. Patients with SAH represents $20-38 \%$ of patients with ARDS among brain-injured patients. ${ }^{[5,14]}$ In brain-injured patients, use of high tidal volume ventilation in the days preceding the development of ARDS was found to be an important risk factor for the development of ARDS. ${ }^{[15]}$ The high tidal volume may function as a second hit on the lung, which is already rendered vulnerable by the systemically released inflammatory mediators from the injured brain [Figure 1]. ${ }^{[7]}$ Furthermore, the lung injury may render the brain more sensitive to acute injuries. ${ }^{[7]}$ Lung protective ventilation strategies using low tidal volume ( $6 \mathrm{ml} / \mathrm{kg}$ predicted body weight) limiting the plateau pressure to $<30 \mathrm{~cm} \mathrm{H}_{2} \mathrm{O}$, and adequate positive end-expiratory pressure (PEEP) has been used to prevent or limit ventilation-induced lung injury. ${ }^{[16]}$ The consequent permissive hypercapnia can be deleterious in patients with raised intracranial pressure (ICP). Smaller studies have shown lung protective ventilation to be safe in patients with SAH. ${ }^{[17,18]}$

Application of PEEP in brain-injured patients can have one of the three responses - either the ICP will increase or decrease or there will be no change. If the applied PEEP results in alveolar recruitment with a consequent reduction in $\mathrm{PaCO}_{2}$, the ICP will decrease. If PEEP induces sole hyperinflation without improvement on ventilation, the ICP may increase. If the applied PEEP

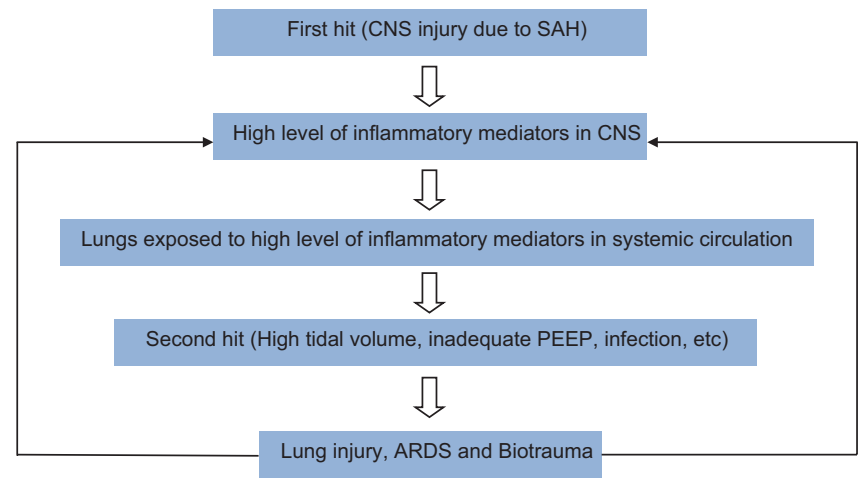

Figure 1: Double-hit model in the patient with brain injury induces alveolar recruitment without a change in $\mathrm{PaCO}_{2}$, the ICP may remain unchanged. ${ }^{[19]}$ The effect of PEEP on cerebral haemodynamics would also depend on the elastance of the lungs. The effect is minimal in patients with low respiratory system compliance, like in patients with ARDS where PEEP is most indicated. ${ }^{[20]}$ It is important to avoid alveolar overdistension and to maintain stable haemodynamics. There are emerging data about the safety of application of PEEP in patients with brain injury. ${ }^{[21]}$ Furthermore, raising the head-end of the bed by $30^{\circ}$ in patients with $\mathrm{SAH}$, who are euvolemic, helps ameliorate the adverse effects of PEEP on ICP and cerebral perfusion pressure (CPP). ${ }^{[22]}$ However, lung recruitment manoeuvre in patients with cerebral injury has been shown to adversely affect the cerebral haemodynamics and metabolism with only a marginal improvement in oxygenation. It should be applied with caution. ${ }^{[23]}$ Larger well-defined studies are need to be performed to evaluate the safety and feasibility of lung protective ventilation strategies in these vulnerable patients and how the management needs to be individualised, weighing the risk and benefit in individual patients.

Prone ventilation has been a standard of care for patients with severe ARDS. The beneficial effects are in the form of improved oxygenation and reduction in mortality when applied for the duration of $>12 \mathrm{~h} /$ day. ${ }^{[24]}$ In patients with SAH, the beneficial of prone ventilation on the improvement of cerebral oxygenation by improving arterial oxygenation seems to overweigh the adverse consequence of increase in ICP and decrease in CPP. Careful monitoring of ICP in the patients during prone ventilation can be prudent. ${ }^{[25]}$

\section{NEUROGENIC PULMONARY OEDEMA}

NPE presents as an acute onset of pulmonary oedema following a significant central nervous system (CNS) insult. Patients usually present with bilateral infiltrates, $\mathrm{PaO}_{2} / \mathrm{FiO}_{2}$ ratio of $<200$, no evidence of left atrial hypertension, presence of severe CNS injury enough to cause significant increase in ICP and the absence of other common causes of ARDS (sepsis, aspiration, massive blood transfusion, etc.). ${ }^{[26]}$ The incidence of NPE ranges from $23 \%$ to $71 \%$ of the hospitalised patients with SAH. Risk factors for developing NPE following SAH are higher clinical and radiographic grade at presentation, increasing age, increasing time to securing of aneurysm and vertebral origin of aneurysm. ${ }^{[27,28]}$ These patients have a higher mortality rate approaching $10 \%{ }^{[29]}$

Sudden, rapid and significant elevation of ICP, followed by intense activation of the sympathetic nervous system with the release of catecholamine, has been considered as a key pathophysiological mechanism for NPE. ${ }^{[26]}$ However, the real pathophysiological events 
at the level of pulmonary vasculature remain elusive. Several clinicopathological explanations have been proposed.

\section{Neurocardiac neurogenic pulmonary oedema} The massive sympathetic discharge following SAH can induce direct myocyte injury causing hypokinesia, diminished lusitropy and diastolic dysfunction, with subsequent cardiogenic pulmonary oedema. ${ }^{[30]}$

\section{Neurohaemodynamic neurogenic pulmonary oedema}

The CNS insult is followed by an abrupt increase in systemic resistance, followed by translocation of fluid from high resistance systemic circulation to low resistance pulmonary circulation and subsequent pulmonary oedema. ${ }^{[31]}$

\section{Blast theory}

During the catecholamine surge, in addition to the increase in hydrostatic pressure, acute rise in pulmonary capillary pressure leads to structural damage of pulmonary endothelium, which leads to vascular leakage and persistent protein-rich pulmonary oedema. ${ }^{[32]}$

\section{Pulmonary venule adrenergic hypersensitivity}

The exaggerated sympathetic discharge directly affects the integrity of pulmonary endothelium integrity, and the oedema develops regardless of the changes in systemic and pulmonary circulation. The presence of $\alpha$ - and $\beta$-adrenoceptors in pulmonary vascular bed supports the theory. ${ }^{[26]}$

The symptoms often resolve spontaneously over 24-48 $\mathrm{h}$ but may persist in patients with ongoing brain injury and raised ICP. Treatment of NPE is mainly focused on treating the underlying neurological condition to limit the sympathetic discharge responsible for lung injury. ${ }^{[26]}$ Various measures for reduction of raised ICP have shown to be beneficial to improve oxygenation. ${ }^{[29]}$ Few case reports have shown the effectiveness of $\alpha$-blocking agents for rapid improvement of patients with NPE. ${ }^{[33]}$

\section{PULMONARY EMBOLISM}

Patients with SAH are at higher risk for deep vein thrombosis (DVT) and pulmonary embolism. The incidence of DVT varies from $1.5 \%$ to $18 \%$. Poor-grade patients are at highest risk. ${ }^{[34,35]}$ The measures to prevent DVT like the use of sequential compression devices should be used routinely in all the patients as soon as they are admitted to hospital. ${ }^{[3]]}$ Venous thromboembolism prophylaxis should be considered with unfractionated heparin at least $24 \mathrm{~h}$ after an aneurysm has been secured by coiling or surgical clipping. ${ }^{[37]}$

\section{CONCLUSION}

Pulmonary complications in patients with aneurysmal $\mathrm{SAH}$ are the major cause of morbidity and mortality. With the improving critical care management of SAH, the clinicians should consider early detection and appropriate management of pulmonary complications to improve patient outcome.

\section{Financial support and sponsorship Nil.}

\section{Conflicts of interest}

There are no conflicts of interest.

\section{REFERENCES}

1. Chen S, Li Q, Wu H, Krafft PR, Wang Z, Zhang JH. The harmful effects of subarachnoid hemorrhage on extracerebral organs. Biomed Res Int 2014;2014:858496.

2. Gruber A, Reinprecht A, Illievich UM, Fitzgerald R, Dietrich W, Czech T, et al. Extracerebral organ dysfunction and neurological outcome after aneurysmal subarachnoid hemorrhage. Crit Care Med 1999;27:505-14.

3. Schuiling WJ, Dennesen PJ, Rinkel GJ. Extracerebral organ dysfunction in the acute stage after aneurysmal subarachnoid hemorrhage. Neurocrit Care 2005;3:1-10.

4. Yoneda $\mathrm{H}$, Nakamura $\mathrm{T}$, Shirao $\mathrm{S}$, Tanaka $\mathrm{N}$, Ishihara $\mathrm{H}$, Suehiro E, et al. Multicentre prospective cohort study in volume management after subarachnoid hemorrhage: Hemodynamic changes according to severity of subarachnoid hemorrhage and cerebral vasospasm. Stroke 2013;44:2155-61.

5. Kahn JM, Caldwell EC, Deem S, Newell DW, Heckbert SR, Rubenfeld GD. Acute lung injury in patients with subarachnoid hemorrhage: Incidence, risk factors, and outcome. Crit Care Med 2006;34:196-202.

6. Friedman JA, Pichelmann MA, Piepgras DG, Mclver JI, Toussaint LG $3^{\text {rd }}$, McClelland RL, et al. Pulmonary complications of aneurysmal subarachnoid hemorrhage. Neurosurgery 2003;52:1025-31.

7. Mrozek S, Constantin JM, Geeraerts T. Brain-lung crosstalk: Implications for neurocritical care patients. World J Crit Care Med 2015;4:163-78.

8. Kollef MH, Morrow LE, Niederman MS, Leeper KV, Anzueto A, Benz-Scott L, et al. Clinical characteristics and treatment patterns among patients with ventilator-associated pneumonia. Chest 2006;129:1210-8.

9. Frontera JA, Fernandez A, Schmidt JM, Claassen J, Wartenberg KE, Badjatia $\mathrm{N}$, et al. Impact of nosocomial infectious complications after subarachnoid hemorrhage. Neurosurgery 2008;62:80-7.

10. Cinotti R, Dordonnat-Moynard A, Feuillet F, Roquilly A, Rondeau N, Lepelletier D, et al. Risk factors and pathogens involved in early ventilator-acquired pneumonia in patients with severe subarachnoid hemorrhage. Eur J Clin Microbiol Infect Dis 2014;33:823-30.

11. Fields LB. Oral care intervention to reduce incidence of ventilator-associated pneumonia in the neurologic intensive care unit. J Neurosci Nurs 2008;40:291-8.

12. Lepelletier D, Roquilly A, Demeure dit latte D, Mahe PJ, Loutrel $\mathrm{O}$, Champin P, et al. Retrospective analysis of the risk factors and pathogens associated with early-onset ventilator-associated pneumonia in surgical-ICU head-trauma patients. J Neurosurg Anesthesiol 2010;22:32-7.

13. Kalil AC, Metersky ML, Klompas M, Muscedere J, Sweeney DA, 
Palmer LB, et al. Management of adults with hospital-acquired and ventilator-associated pneumonia: 2016 clinical practice guidelines by the Infectious Disease Society of America and the American Thoracic Society. Clin Infect Dis 2016;63:e61-111.

14. Veeravagu A, Chen YR, Ludwig C, Rincon F, Maltenfort M, Jallo J, et al. Acute lung injury in patients with subarachnoid hemorrhage: A nationwide inpatient sample study. World Neurosurg 2014;82:e235-41.

15. Mascia L, Zavala E, Bosma K, Pasero D, Decaroli D, Andrews P, et al. High tidal volume is associated with the development of acute lung injury after severe brain injury: An international observational study. Crit Care Med 2007;35:1815-20.

16. Slutsky AS. Lung injury caused by mechanical ventilation. Chest 1999;116 1 Suppl: 9S-15S.

17. Petridis AK, Doukas A, Kienke S, Maslehaty H, Mahvash M, Barth $\mathrm{H}$, et al. The effect of lung-protective permissive hypercapnia in intracerebral pressure in patients with subarachnoid haemorrhage and ARDS. A retrospective study. Acta Neurochir (Wien) 2010;152:2143-5.

18. Westermaier T, Stetter C, Kunze E, Willner N, Holzmeier J, Kilgenstein $\mathrm{C}$, et al. Controlled transient hypercapnia: A novel approach for the treatment of delayed cerebral ischemia after subarachnoid hemorrhage? J Neurosurg 2014;121:1056-62.

19. Mascia L, Grasso S, Fiore T, Bruno F, Berardino M, Ducati A. Cerebro-pulmonary interactions during the application of low levels of positive end-expiratory pressure. Intensive Care Med 2005;31:373-9.

20. Caricato A, Conti G, Della Corte F, Mancino A, Santilli F, Sandroni C, et al. Effects of PEEP on the intracranial system of patients with head injury and subarachnoid hemorrhage: The role of respiratory system compliance. J Trauma 2005;58:571-6.

21. Boone MD, Jinadasa SP, Mueller A, Shaefi S, Kasper FM, Hanafy KA, et al. The effects of positive end-expiratory pressure on intracranial pressure and cerebral hemodynamics. Neurocrit Care 2016. [Epub ahead of print].

22. Schulz-Stuibner $S$, Thiex $R$. Raising the head-of-bed by 30 degrees reduces ICP and improves CPP without compromising cardiac output in euvolemic patients with traumatic brain injury and subarachnoid haemorrhage: A practice audit. Eur J Anaesthesiol 2006;23:177-80.

23. Bein T, Kuhr LP, Bele S, Ploner F, Keyl C, Taeger K. Lung recruitment maneuver in patients with cerebral injury: Effects on intracranial pressure and cerebral metabolism. Intensive Care Med 2002;28:554-8.

24. Hu SL, He HL, Pan C, Liu AR, Liu SQ, Liu L, et al. The effect of prone positioning on mortality in patients with acute respiratory distress syndrome: A meta-analysis of randomized controlled trials. Crit Care 2014;18:R109.

25. Reinprecht A, Greher $M$, Wolfsberger S, Dietrich $W$,
Illievich UM, Gruber A. Prone position in subarachnoid hemorrhage patients with acute respiratory distress syndrome: Effects on cerebral tissue oxygenation and intracranial pressure. Crit Care Med 2003;31:1831-8.

26. Davison DL, Terek M, Chawla LS. Neurogenic pulmonary edema. Crit Care 2012;16:212.

27. Solenski NJ, Haley EC Jr., Kassell NF, Kongable G, Germanson T, Truskowski L, et al. Medical complications of aneurysmal subarachnoid hemorrhage: A report of the multicenter, cooperative aneurysm study. Participants of the Multicenter Cooperative Aneurysm Study. Crit Care Med 1995;23:1007-17.

28. Ochiai H, Yamakawa Y, Kubota E. Deformation of the ventrolateral medulla oblongata by subarachnoid hemorrhage from ruptured vertebral artery aneurysms causes neurogenic pulmonary edema. Neurol Med Chir (Tokyo) 2001;41:529-34 .

29. Fontes RB, Aguiar PH, Zanetti MV, Andrade F, Mandel M, Teixeira MJ. Acute neurogenic pulmonary edema: Case reports and literature review. J Neurosurg Anesthesiol 2003; $15: 144-50$

30. Mayer SA, Lin J, Homma S, Solomon RA, Lennihan L, Sherman D, et al. Myocardial injury and left ventricular performance after subarachnoid hemorrhage. Stroke 1999;30:780-6.

31. Sarnoff SJ, Sarnoff LC. Neurohemodynamics of pulmonary edema. II. The role of sympathetic pathways in the elevation of pulmonary and systemic vascular pressures following the intracisternal injection of fibrin. Circulation 1952;6:51-62.

32. Theodore J, Robin ED. Speculations on neurogenic pulmonary edema (NPE). Am Rev Respir Dis 1976;113:405-11.

33. Wohns RN, Tamas L, Pierce KR, Howe JF. Chlorpromazine treatment for neurogenic pulmonary edema. Crit Care Med 1985;13:210-1.

34. Mack WJ, Ducruet AF, Hickman ZL, Kalyvas JT, Cleveland JR, Mocco J, et al. Doppler ultrasonography screening of poor-grade subarachnoid hemorrhage patients increases the diagnosis of deep venous thrombosis. Neurol Res 2008;30:889-92.

35. Ray WZ, Strom RG, Blackburn SL, Ashley WW, Sicard GA, Rich KM. Incidence of deep venous thrombosis after subarachnoid hemorrhage. J Neurosurg 2009;110:1010-4.

36. Diringer MN, Bleck TP, Claude Hemphill J $3^{\text {rd }}$, Menon D, Shutter L, Vespa P, et al. Critical care management of patients following aneurysmal subarachnoid hemorrhage: Recommendations from the Neurocritical Care Society's Multidisciplinary Consensus Conference. Neurocrit Care 2011;15:211-40.

37. Nyquist $P$, Bautista $C$, Jichici D, Burns J, Chhangani S, DeFilippis $\mathrm{M}$, et al. Prophylaxis of venous thrombosis in neurocritical care patients: An evidence-based guideline: A statement for healthcare professionals from the Neurocritical Care Society. Neurocrit Care 2016;24:47-60. 